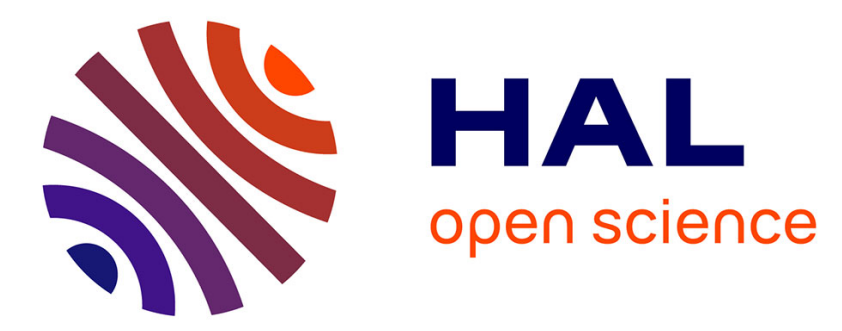

\title{
Rapid determination of the thermophysical properties of various materials. Method of the hot plane film
}

\author{
Pierre Mounanga, G. Bastian, G. Bron, R. Coué
}

\section{To cite this version:}

Pierre Mounanga, G. Bastian, G. Bron, R. Coué. Rapid determination of the thermophysical properties of various materials. Method of the hot plane film. European Physical Journal: Applied Physics, 2004, 26 (1), pp.65 - 72. 10.1051/epjap:2004010 . hal-01007230

\section{HAL Id: hal-01007230 \\ https://hal.science/hal-01007230}

Submitted on 22 Jan 2017

HAL is a multi-disciplinary open access archive for the deposit and dissemination of scientific research documents, whether they are published or not. The documents may come from teaching and research institutions in France or abroad, or from public or private research centers.
L'archive ouverte pluridisciplinaire HAL, est destinée au dépôt et à la diffusion de documents scientifiques de niveau recherche, publiés ou non, émanant des établissements d'enseignement et de recherche français ou étrangers, des laboratoires publics ou privés. 


\title{
Rapid determination of the thermophysical properties of various materials. Method of the hot plane film
}

\author{
P. Mounanga ${ }^{\mathrm{a}}$, G. Bastian, G. Bron, and R. Coué \\ Laboratoire de Génie Civil de Nantes Saint-Nazaire (L.G.C.N.S-N.), Institut Universitaire de Technologie, \\ département Génie Civil, BP 420, 44606 Saint-Nazaire Cedex, France
}

\begin{abstract}
A new technical approach of a traditional method for the rapid (and therefore, non interfering) determination of the thermophysical properties of porous materials likely, a priori, to undergo coupled heat and moisture transfers is described. The improvements discussed here consist in the use of a heater film suiting the "method of the hot plane film" especially well. A comparison with former works by one of the method's author is made. Finally, the updated method is applied to a variety of particularly significant materials.
\end{abstract}

\section{Introduction}

Most of the civil engineering materials (also called "geomaterials") are porous, and, therefore, can absorb, retain and release water under liquid or vapour phases. They can be subjected to coupled heat and moisture transfers. The transfer-involved independent variables are, if the materials are non-saturated, the temperature, on the one hand, and the moisture content, the suction [1] or the relative humidity, if the materials are hygroscopic [2], on the other hand. Moreover, according to Moyne [3], a third variable (the pressure of the gaseous phase (air + vapour)) is necessary. However, at least as regards civil engineering researches, situations where this variable occurs are exceptional [4]. The use of geomaterials, in particular for durability evaluations, requires to know their transfer properties. Several measurement methods for parameters characterizing heat and moisture transfers within hygroscopic materials have been developed at the laboratory [5-8]. Later, some methods suiting the case of close to saturation and weakly permeable materials have been perfected [9]. Bastian's former works on the thermophysical property rapid determination using the method of the hot plane film [10] are resumed and improved to be now used in recent [11] or currently in progress studies conducted on very fresh cement pastes (less than $24 \mathrm{~h}$ ). If the method is difficult to apply to a fresh cement paste because of the strong heat release due to the water-cement reaction of hydration, its relevance, on the other hand, is unquestionable for porous or not, heat stable materials with mean thermal conductivity (from 0.2 to $3 \mathrm{~W} \mathrm{~m}^{-1} \mathrm{~K}^{-1}$ ). The technical changes brought about in the initial method and their application to different materials are presented here. The problem of thermophysical property determination for porous materials having a certain moisture content is first evoked.

\section{Problematics. Theory formulation}

\subsection{Transfer equations}

By neglecting pressure variations of the gaseous phase and hysteresis phenomena, and by assuming the structural changes and the concomitant reaction of hydration to be slow and weak, respectively (which becomes true $24 \mathrm{~h}$ after casting for cement-based materials), the transfer equations, in the case of vertical transfers with an upward vertical $\mathrm{O} x$-axis only, can be written:

$$
\begin{aligned}
\rho_{0} c \frac{\partial T}{\partial t} & =\nabla \cdot\left(\lambda \nabla T+\rho_{l} L_{v} D_{\theta v} \nabla \theta\right) \\
\frac{\partial \theta}{\partial t} & =\nabla \cdot\left(D_{\theta} \nabla \theta+D_{T v} \nabla T\right)+\frac{\partial K_{l}}{\partial z}
\end{aligned}
$$

$\theta$, the volume moisture content and $T$, the temperature, are independent variables. $\rho_{0}$ is the density of the dry material (i.e., which has been incubated), $\rho_{l}$ is the density of water, $c$ is the wet material mass heat capacity $\left[\mathrm{J} \mathrm{kg}^{-1} \mathrm{~K}^{-1}\right]$, and $L_{v}$ is the water latent heat of vaporization $\left[\mathrm{J} \mathrm{m}^{-3}\right]$.

$D_{\theta}$ is the total hydrous diffusivity, $D_{T v}$ and $D_{\theta v}$ are vapour diffusion coefficients under temperature and 
moisture content gradients, and $K_{l}$ is the hydraulic conductivity.

$\lambda(\theta, T)\left[\mathrm{W} \mathrm{m}^{-1} \mathrm{~K}^{-1}\right]$, the "apparent" thermal conductivity $[1,3]$ results from the cumulative effect of pure conduction phenomena (conduction is considered as pure at $0{ }^{\circ} \mathrm{C}\left(\lambda_{0}(\theta)\right.$ : Fourier's law) and phase change heat releases due to vapour transfers. We then have: $\lambda=\lambda_{0}+\rho_{l} L_{v} D_{T v}$.

As shown by Daïan [13], unlike suction $\left(\nabla \cdot\left(D_{\theta} \nabla \theta\right)\right)$, $\partial K_{l} / \partial z$, which corresponds to gravity is generally neglected in the case of cement materials.

Moisture diffusion being much slower than the diffusion of heat within the cement-based materials studied, rapid dynamic measurement methods, which would not generate interferences in the moisture content (contrary to static methods like "the guarded hot plate"), can be used here. Equations $(1,2)$ then reduce to:

$$
\rho_{0} c \frac{\partial T}{\partial t}=\nabla \cdot(\lambda \nabla T) .
$$

If thermal interferences are weak, this equation can be linearized. We then obtain the classical heat diffusion equation:

$$
\rho_{0} c \frac{\partial T}{\partial t}=\lambda \nabla^{2} T
$$

The determination of $\lambda$ (apparent thermal conductivity), of $\rho_{0} c$ (volume heat capacity), of the ratios $a=\lambda / \rho_{0} c$ (thermal diffusivity) and $b=\left(\lambda \rho_{0} c\right)^{1 / 2}$ (thermal effusivity) is carried out with a simplified experimental set-up (simple geometry and boundary conditions - thermal flux step, for instance) and by solving analytically the heat transfer equation, and, finally, by comparing the experimental and theoretical results.

\subsection{Method of the hot plane film}

One side of a $l$ thick cement material plate is heated using a film generating a power $P\left[\mathrm{~W} \mathrm{~m} \mathrm{~m}^{-2}\right]$ from the instant $t=0$. The film/plate set is placed between two thick insulation plates considered as perfect. Two thermocouples are used to measure the temperatures on both sides of the plate (heated and non-heated faces). With regard to the configuration, the solution of equation (4) gives the temperature theoretical evolutions of both faces, $T_{h}$ and $T_{n h}$, respectively. If $t<3 l^{2} / a \pi^{2}$, then

$$
T_{h}=\frac{2 P}{b \sqrt{\pi}} \sqrt{t}
$$

and $(6,7)$ if $t>3 l^{2} / a \pi^{2}$

$$
\begin{aligned}
T_{h} & =P\left[\frac{t}{\rho_{0} c l}+\frac{l}{3 \lambda}\right] \\
T_{n h} & =P\left[\frac{t}{\rho_{0} c l}-\frac{l}{6 \lambda}\right] .
\end{aligned}
$$

Insofar as the temperature experimental evolutions satisfactorily agree with the theoretical predictions, the values of $\lambda, \rho_{0} c, a$ and $b$ can be deduced (the "anamorphose" study of $T_{h}$ vs. $t^{1 / 2}$, for instance, introduces the value of the effusivity, $\left.b\left[\mathrm{~J} \mathrm{~s}^{-1 / 2} \mathrm{~m}^{-2} \mathrm{~K}^{-1}\right]\right) . \Delta$ being some linear variations.

Equation (5) gives:

$$
b=\frac{2 P \Delta(\sqrt{t})}{\sqrt{\pi} \Delta T}
$$

equations $(6,7)$ give:

$$
\lambda=\frac{P l}{2 \Delta T}
$$

and

$$
\rho_{0} c=\frac{P \Delta t}{l \Delta T}
$$

and consequently:

$$
a=\frac{l^{2}}{2 \Delta t}
$$

and

$$
b=\frac{P}{\Delta T} \sqrt{\frac{\Delta t}{2}} .
$$

\section{Experimental setting}

\subsection{Heating film}

A former experimental set-up has been improved for this research [10]. Data acquisition system changes are not described here. The objective here is to describe the use of higher performance heating films. Because thermal inertia of the previous films $\left(\mathrm{TRESCO}^{\circledR}{ }^{\circledR}\right.$ and $\mathrm{SEMME}^{\circledR}$ ), traditionally used for domestic low temperature ceiling panel heating, is not insignificant, and since they suit small-scale set-ups with difficulty, the performances of an alternative paper coated with a semiconducting graphited material (TELEDELTOS paper) deserve some studies. This paper has been used for many years now to represent two-dimensional stationary thermal fields [14]. The paper, through which a weak current generated by silverlacquered electrodes run, and which simulates the boundary conditions of the thermal conduction problem, is used to determine equipotential lines. On conditions that the voltage, which is applied between both opposite edges, is high enough, the TELEDELTOS paper is precious to heat material samples.

\subsection{Set-up}

The objective of the set-up presented in Figures 1 and 2 is:

- to characterize the TELEDELTOS paper as heating film, i.e., to measure its electrical resistance according to its surface temperature (as a rule, the resistance also depends on the relative humidity of the surrounding air [14] but, since the laboratory is air-conditioned, it is considered constant here); 


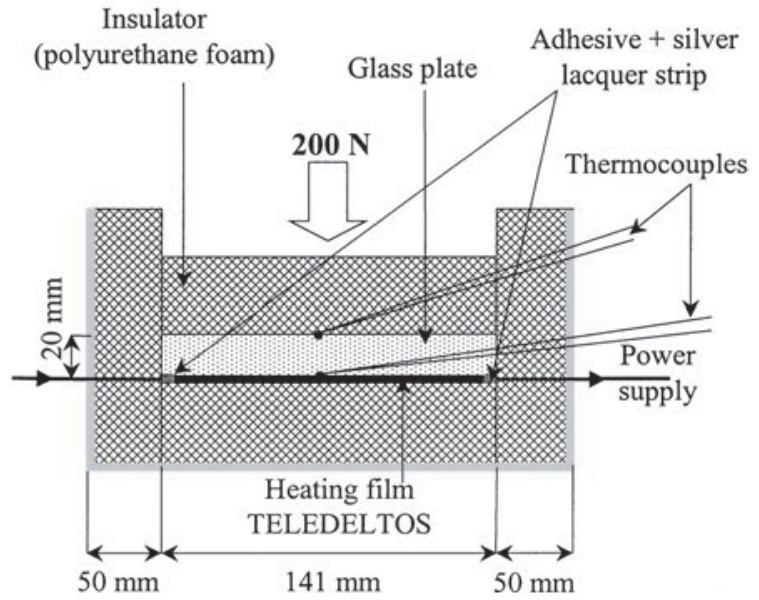

Fig. 1. Thermal scheme.

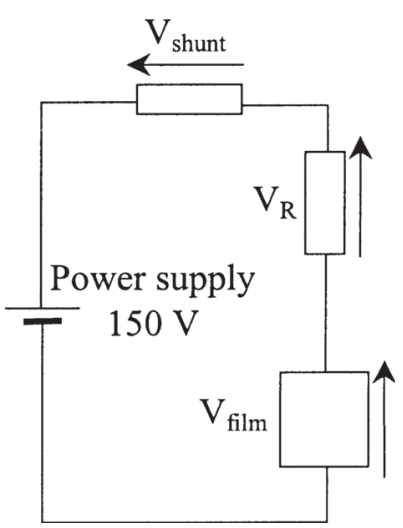

Fig. 2. Wiring scheme.

- to heat a glass plate used as reference material whose thermal properties have previously been determined using two independent methods [10]. The dimensions of the plate (as well as the samples studied later) are $141 \times 141 \times 20 \mathrm{~mm}$ (that is to say a surface of $200 \mathrm{~cm}^{2}$ ). In fact, the plate is a combination of two $10-\mathrm{mm}$ thick glass plates glued together using specific grease maintaining a good thermal contact.

Two type $K$ thermocouples, placed on upper and bottom sides, respectively, and connected to a data acquisition station, are used to record the temperature evolution as a function of time. Data are exported in an EXCEL format. The set-up is thermally insulated using polyurethane foam, which can be cut precisely.

The wiring scheme of Figure 2 consists of a direct tension of $150 \mathrm{~V}$, supplied by a regulated power system and applied to a set of three series resistors, at the terminals of which tensions are measured, of the film with the two lacquered electrodes on both opposite edges, of a shunt to determine the amount of current (approximately $30 \mathrm{~mA}$ ) and of a rheostat regulated to a resistance value more or less equal to that of the film. Under these conditions (i.e., constant voltage), an elementary calculation reveals that although the film resistance varies a little during heating, the released power due to the Joule effect, on the other hand, remains approximately constant.

This consistency, verified by calculating the product of the voltage measured at the film terminals by the current intensity through the shunt, is essential. Flux density consistency, indeed, is one of the basic hypotheses of the thermal property measurement method.

The preliminary set-up, with which the reference glass plate is studied, is then modified so as to heat the reference sample and a sample from another material simultaneously (Fig. 3). The heating film surface being double, the voltage emitted by the power supply is regulated to $200 \mathrm{~V}$ (Fig. 4). Measurements of the either absolute (like for glass) or relative (as described below) values of the material thermal properties can then be carried out.

\section{Experimental results}

\subsection{Heating film}

Figure 5 presents the calibration curve showing the relationship between the resistance of a 141-mm TELEDELTOS paper square strip and its temperature.

Figure 6 confirms the consistency of the released power.

\subsection{Thermophysical properties of the reference glass plate}

Figure 7 presents the evolution of the temperatures, $T_{h}$ and $T_{n h}$, according to time, from which the values of $\lambda, \rho_{0} c$, then $a$ and $b$ are deduced. Similarly, $T_{h}$ vs. $\sqrt{t}$ and finally effusivity $b$ again are obtained from Figure 8 .

Table 1 gives a review of the experimental results of the glass thermophysical properties and a comparison with former results achieved with the same sample.

Former and new results satisfactorily agree. Furthermore, thanks to a more modern acquisition system, data processing is automated.

The comparison between Figures 8 and 9 reveals a reduction in the thermal inertia of the new heating film, which is, moreover, much easier to implement. Paper strips fitting the required dimensions are easily cut. Furthermore, considering the paper resistivity, the electrical power supply does not pose problems for small size sheets.

\subsection{Application to different materials}

The materials studied here are characterized by their mean conductivity (i.e., they are not insulating and not metallic). For some, which are not porous (glass and PVC), the measured conductivity is called "real". For others (wood, sand with various moisture contents, clay, fresh cement paste), which are porous, the measured conductivity is called "apparent". Wood, moreover, is anisotropic.

Among these materials, wood, dry sand and PVC are low heat conductors. In [10], Bastian has shown that, for 


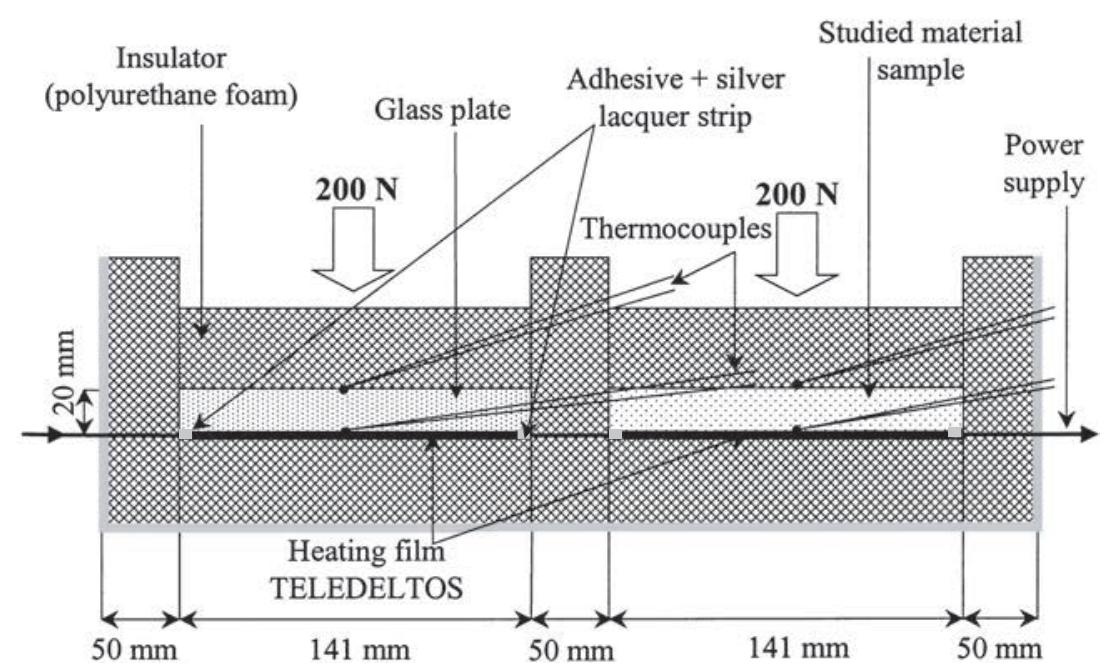

Fig. 3. Thermal scheme with both heating films connected in series.

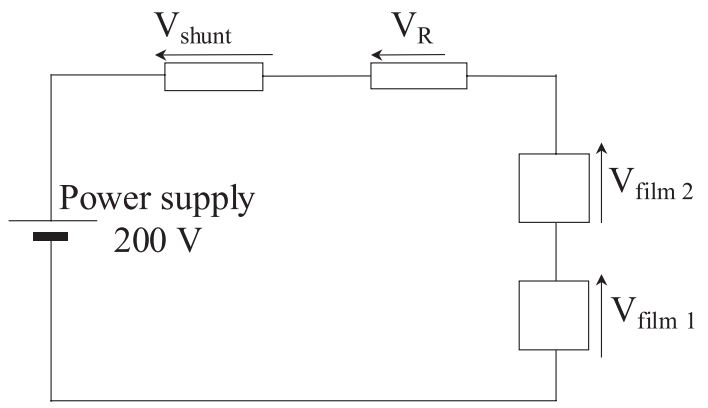

Fig. 4. Wiring scheme with both heating films.

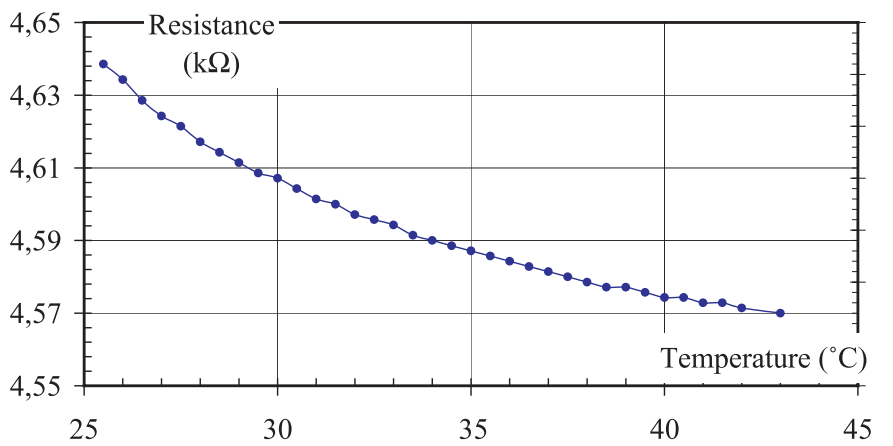

Fig. 5. Evolution of the resistance of the TELEDELTOS film during heating.

these materials, the choice of the set-up insulator can have an impact on the thermophysical property measurements because a non-negligible portion of the heat flux released by the film can be absorbed by the insulator. The author, thus, demonstrates that, for a ratio of the insulator effusivity $\left(b_{2}\right)$ to the material effusivity $\left(b_{1}\right)$ lower than 0.02 , the error introduced by the insulator is negligible. Beyond this value, the results must be corrected.

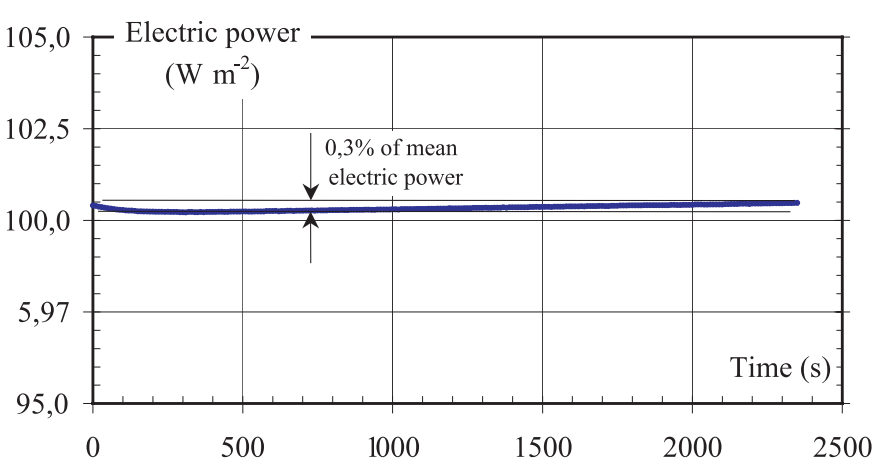

Fig. 6. Variation of the electric power released within the heating film during test.

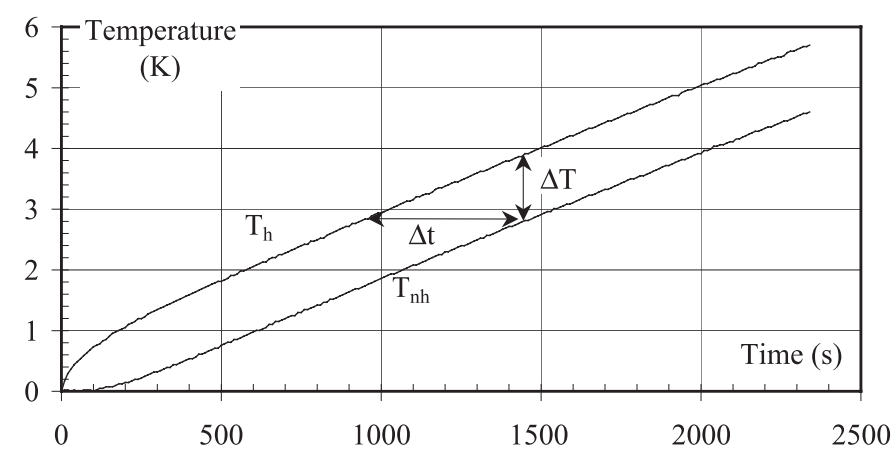

Fig. 7. Evolution of temperatures $T_{h}$ and $T_{n h}$ vs. $t$.

4.3.1 Determination of the error due to the imperfect insulation of both external faces

We set:

$$
b^{*}=\frac{b_{2}}{b_{1}} ; \quad T^{*}=\frac{T \lambda}{P l} ; \quad \tau=\frac{l^{2}}{a \pi^{2}} ; \quad t^{*}=\frac{t}{\tau} .
$$

Let $\Delta T^{*}$ be the temperature difference between both external faces of the studied sample. In the case of an imperfect insulation $\left(b^{*} \neq 0\right)$, for $\lambda, \rho_{0} c, a$ and $b$, we 
Table 1. Comparison between the experimental results obtained for glass using the new and the former set-up.

\begin{tabular}{lccc}
\hline Thermophysical units & {$[10]$} & {$[10]$} & Current results \\
\hline$\lambda\left[\mathrm{W} \mathrm{m}^{-1} \mathrm{~K}^{-1}\right]$ & Hot guarded plate & Dynamic measurements & \\
$\rho_{0} c\left[\mathrm{~J} \mathrm{~K}^{-1} \mathrm{~m}^{-3}\right]$ & 1.00 & 1.00 & 0.99 \\
$a\left[\mathrm{~m}^{2} \mathrm{~s}^{-1}\right]$ & - & $2.30 \times 10^{6}$ & $2.21 \times 10^{6}$ \\
$b=\sqrt{\lambda \rho_{0} c}\left[\mathrm{~W} \mathrm{~s}^{1 / 2} \mathrm{~m}^{-2} \mathrm{~K}^{-1}\right]$ & - & $4.35 \times 10^{-7}$ & $4.53 \times 10^{-7}$ \\
$b\left[\mathrm{~W} \mathrm{~s}^{1 / 2} \mathrm{~m}^{-2} \mathrm{~K}^{-1}\right]$ & - & 1520 & 1479 \\
(direct measurement) & - & 1490 & 1496 \\
\hline
\end{tabular}

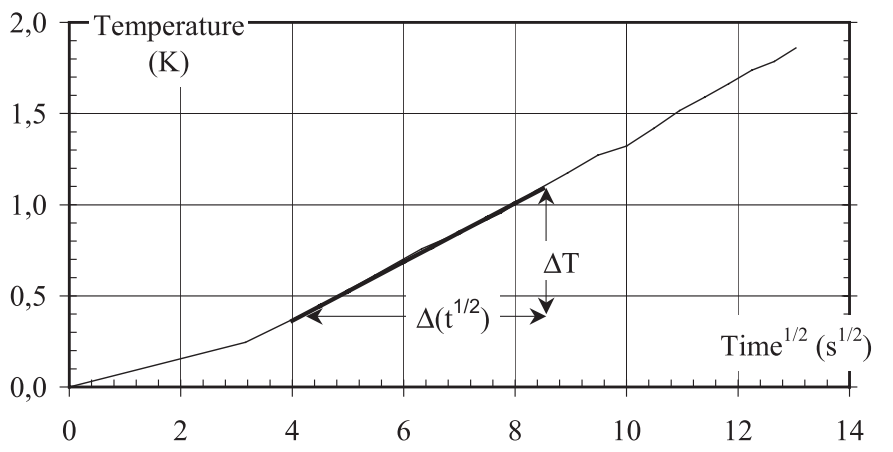

Fig. 8. Evolution of the temperature $T_{h}$ vs. $\sqrt{t}$.

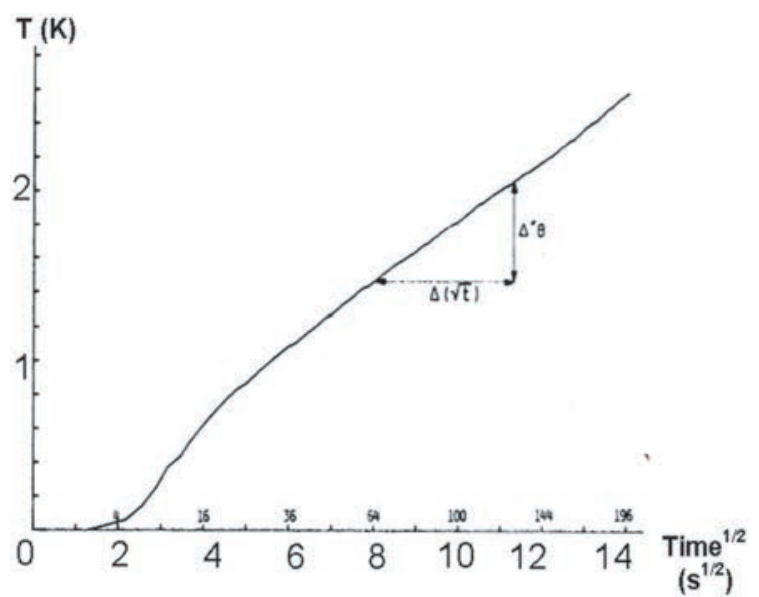

Fig. 9. Evolution of the temperature $T_{h}$ vs. $\sqrt{t}$ recorded using the former set-up [10].

obtain [10]:

$$
\begin{aligned}
\lambda & =\frac{P l}{2 \Delta T} \frac{\Delta T_{b^{*} \neq 0}^{*}}{\Delta T_{b^{*}=0}^{*}} \\
\rho_{0} c & =\frac{P \Delta t}{l \Delta T} \frac{\Delta T_{b^{*} \neq 0}^{*}}{\Delta T_{b^{*}=0}^{*}} \frac{\Delta t_{b^{*}=0}}{\Delta t_{b^{*} \neq 0}} \\
b_{1} & =\frac{2 P \sqrt{t}}{\sqrt{\pi} T(0, t)}-b_{2} \\
a & =\frac{l^{2}}{2 \Delta t} .
\end{aligned}
$$

Table 2. Polyurethane foam thermal properties.

\begin{tabular}{lr}
\hline Thermal conductivity $\left[\mathrm{W} \mathrm{m}^{-1} \mathrm{~K}^{-1}\right]$ & 0.030 \\
Mass heat capacity $\left[\mathrm{J} \mathrm{K}^{-1} \mathrm{~kg}^{-1}\right]$ & 840 \\
Density $\left[\mathrm{kg} \mathrm{m}^{-3}\right]$ & 35 \\
Thermal effusivity $\left[\mathrm{W} \mathrm{s}^{1 / 2} \mathrm{~m}^{-2} \mathrm{~K}^{-1}\right]$ & 30 \\
\hline
\end{tabular}

The properties of the insulator used for this research are presented in Table 2.

For instance, for the wood plate heated in the normal direction to the grain (Tab. 3), the correction on the experimental results is approximately $5 \%$.

\subsubsection{Application to PVC, wood, clay and sand}

The corrected results obtained with these materials are plotted in Table 3.

Two different methods can be used for the determination of the various physical units: first, like for glass, by using equations $(7,11)$ separately, an absolute determination is conducted, which implies that the applied flux density, $P$, is known; or, like in $[10]$ where equations $(8,10)$, within which time is eliminated, are applied to two samples of materials A and B with the same thickness and heated simultaneously. We then obtain:

- short periods of time: equation (8) gives

$$
b_{B}=b_{A}\left(\Delta T_{h A} / \Delta T_{h B}\right) \text {; }
$$

- long periods of time: equation (10) gives

$$
\left(\rho_{0} c\right)_{B}=\left(\rho_{0} c\right)_{A}\left(\Delta T_{h A} / \Delta T_{h B}\right) .
$$

Figure 10 is an illustration of relative determination using PVC, glass being the reference material.

Relative determination results satisfactorily agree with the direct measurement results of Table 3. Globally, the thermophysical property values measured for all materials are in good agreement with data from the literature [15-20]. For dry sand, De Vries, mentioned by Farouki [15], obtains a thermal conductivity of approximately $0.30 \mathrm{~W} \mathrm{~m}^{-1} \mathrm{~K}^{-1}$, whereas the information on sea sand found in the Aide Mémoire du Thermicien [16] gives values within the range $0.35-0.43 \mathrm{~W} \mathrm{~m}^{-1} \mathrm{~K}^{-1}$.

Mixing of water and sand increases the material thermal conductivity significantly because of the formation 
Table 3. Experimental results.

\begin{tabular}{|c|c|c|c|c|c|c|}
\hline Materials & $\mathrm{PVC}$ & $\begin{array}{l}\text { Wood } \\
\text { (normal to } \\
\text { the grain of } \\
\text { the wood) }\end{array}$ & $\begin{array}{l}\text { Wood } \\
\text { (with the } \\
\text { grain) }\end{array}$ & $\begin{array}{l}\text { Saturated } \\
\text { clay }\end{array}$ & Dry sand & $\begin{array}{l}\text { Moist sand } \\
\text { (moisture } \\
\text { content: } \\
10 \%)\end{array}$ \\
\hline$\rho_{0}\left[\mathrm{~kg} \mathrm{~m}^{-3}\right]$ & 1453 & 410 & 410 & 1348 & 1611 & 1766 \\
\hline$\lambda\left[\mathrm{W} \mathrm{m}^{-1} \mathrm{~K}^{-1}\right]$ & 0.20 & 0.13 & 0.34 & 0.92 & 0.32 & 2.26 \\
\hline$\rho_{0} c\left[\mathrm{~J} \mathrm{~K}^{-1} \mathrm{~m}^{-3}\right]$ & $1.57 \times 10^{6}$ & $7.72 \times 10^{5}$ & $7.58 \times 10^{5}$ & $3.85 \times 10^{6}$ & $1.36 \times 10^{6}$ & $2.02 \times 10^{6}$ \\
\hline $\begin{array}{l}a=\lambda / \rho_{0} c \\
{\left[\mathrm{~m}^{2} \mathrm{~s}^{-1}\right]}\end{array}$ & $1.25 \times 10^{-7}$ & $1.68 \times 10^{-7}$ & $4.36 \times 10^{-7}$ & $2.39 \times 10^{-7}$ & $2.35 \times 10^{-7}$ & $11.2 \times 10^{-7}$ \\
\hline $\begin{array}{l}a \text { (direct } \\
\text { measurement) } \\
{\left[\mathrm{m}^{2} \mathrm{~s}^{-1}\right]}\end{array}$ & $1.17 \times 10^{-7}$ & $1.62 \times 10^{-7}$ & $4.33 \times 10^{-7}$ & $2.53 \times 10^{-7}$ & $2.31 \times 10^{-7}$ & $11.1 \times 10^{-7}$ \\
\hline $\begin{array}{l}b=\sqrt{\lambda \rho_{0} c} \\
{\left[\mathrm{~W} \mathrm{~s}^{1 / 2} \mathrm{~m}^{-2} \mathrm{~K}^{-1}\right]}\end{array}$ & 555 & 298 & 511 & 1882 & 663 & 2135 \\
\hline $\begin{array}{l}b \text { (direct } \\
\text { measurement) } \\
{\left[\mathrm{W} \mathrm{s}^{1 / 2} \mathrm{~m}^{-2} \mathrm{~K}^{-1}\right]}\end{array}$ & 555 & 318 & 482 & 1889 & 682 & 2191 \\
\hline $\begin{array}{l}b \text { (corrected } \\
\text { using }(\text { Eq. }(15)) \\
{\left[\mathrm{W} \mathrm{s}^{1 / 2} \mathrm{~m}^{-2} \mathrm{~K}^{-1}\right]}\end{array}$ & 525 & 288 & 452 & 1859 & 652 & 2161 \\
\hline $\begin{array}{l}b \text { (obtained } \\
\text { using }(\text { Eq. }(17)) \\
{\left[\mathrm{W} \mathrm{s}^{1 / 2} \mathrm{~m}^{-2} \mathrm{~K}^{-1}\right]}\end{array}$ & 554 & 318 & 491 & 1873 & 664 & 2187 \\
\hline $\begin{array}{l}\rho_{0} c \text { (obtained } \\
\text { using (Eq. (18)) } \\
{\left[\mathrm{J} \mathrm{K}^{-1} \mathrm{~m}^{-3}\right]}\end{array}$ & $1.52 \times 10^{6}$ & $7.71 \times 10^{5}$ & $7.63 \times 10^{5}$ & $3.79 \times 10^{6}$ & $1.42 \times 10^{6}$ & $2.07 \times 10^{6}$ \\
\hline
\end{tabular}

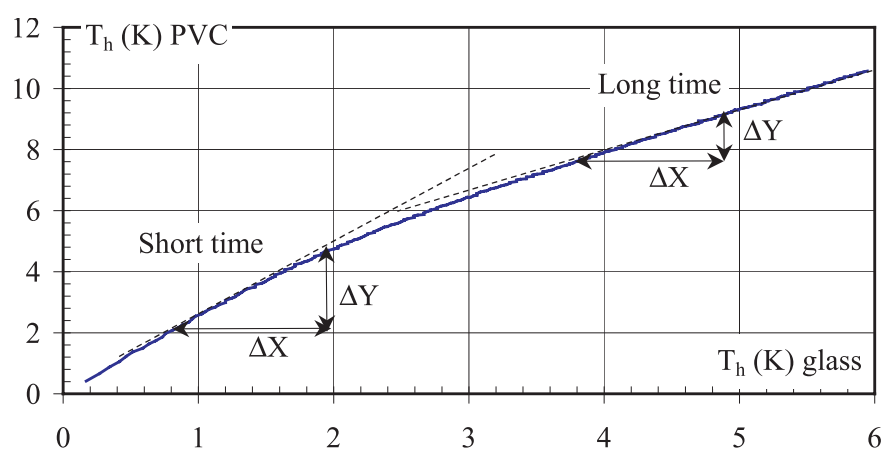

Fig. 10. $X$ and $Y$ recordings of glass and PVC temperatures.

of water bridges between the grains, which further heat transfers inside the mixture [15]. For a sand with a moisture content of $10 \%$, the thermal conductivity obtained by De Vries is approximately $2 \mathrm{~W} \mathrm{~m}^{-1} \mathrm{~K}^{-1}$. The composition and the particle size distribution, which can vary depending on the sand, accounts for the difference between this value and the value achieved here.

The thermophysical property values achieved for PVC agree with the following values found in the literature [16], variations in values being due to the differences in the composition of the materials: at $20^{\circ} \mathrm{C}, \lambda=0.166 \mathrm{~W} \mathrm{~m}^{-1} \mathrm{~K}^{-1}$, $\rho_{0} c=1.38 \times 10^{6} \mathrm{~J} \mathrm{~K}^{-1} \mathrm{~m}^{-3}$ and $a=1.20 \times 10^{-7} \mathrm{~m}^{2} \mathrm{~s}^{-1}$. Moreover, for a PVC with a density within the range 1300-1400 $\mathrm{kg} \mathrm{m}^{-3}$, the thermal conductivity obtained by Hazard et al. is $0.20 \mathrm{~W} \mathrm{~m}^{-1} \mathrm{~K}^{-1}[17]$.
The thermophysical properties of clay are highly dependent upon the material moisture content [15]. Both thermal conductivity and volume heat increase when the moisture content increases. The moisture content of the saturated clay studied here is $123 \%$. In a former study, conducted on the same material save for the moisture content, which was lower, the values obtained were $\lambda=$ $0.70 \mathrm{~W} \mathrm{~m}^{-1} \mathrm{~K}^{-1}, \rho_{0} c=2.29 \times 10^{6} \mathrm{~J} \mathrm{~K}^{-1} \mathrm{~m}^{-3}$ [18], which is lower than the values obtained here. This difference is probably due to the difference in the moisture content.

The wooden material studied (fir) is highly anisotropic (Fig. 11). In order to examine the impact of this on the values of its heat transfer parameters, measurements are carried out on two plates with the same dimensions, one being cut with the grain and the other perpendicularly. Depending on the cutting direction, the thermal conductivity varies with a multiplying factor of three, whereas volume heat remains identical whatever the configuration. This result is not surprising since volume heat depends on the material composition only, whereas the thermal conductivity depends on both material composition and structure. The results for wood agree with those found in the literature. Thus, the thermal conductivity obtained by Hazard et al. [17] and Götz et al. [19] for fir tree wood (with a density ranging between 300 and $450 \mathrm{~kg} \mathrm{~m}^{-3}$ for Hazard et al.) is $0.14 \mathrm{~W} \mathrm{~m}^{-1} \mathrm{~K}^{-1}$ and $0.12 \mathrm{~W} \mathrm{~m}^{-1} \mathrm{~K}^{-1}$, respectively. Few pieces of information, on the other hand, are available in the literature regarding the thermal conductivity of wood cut with the grain. The LIGNUM (The 


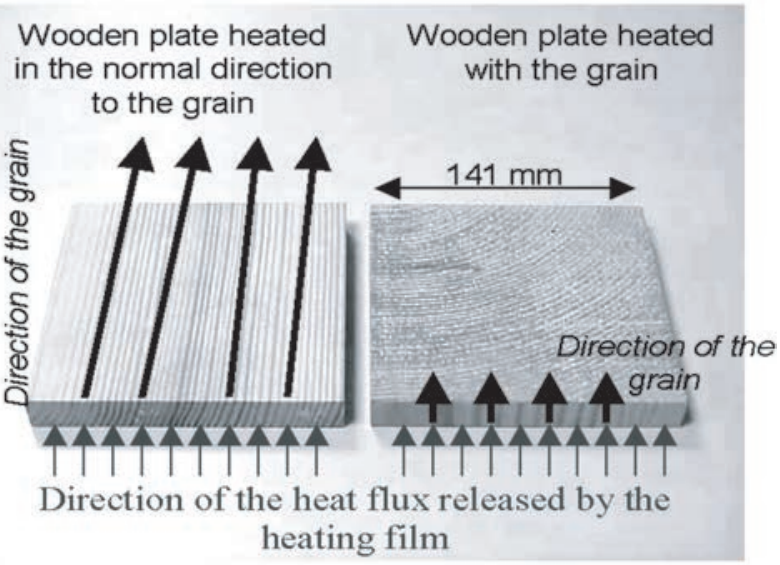

Fig. 11. Photographs of the wooden plates showing their anisotropic features.

Swiss Union for Wood) gives a value of $\lambda$ ranging between 0.25 and $0.29 \mathrm{~W} \mathrm{~m}^{-1} \mathrm{~K}^{-1}[20]$.

\subsubsection{Application to fresh cement paste}

The tests conducted on fresh cement pastes with the setup presented in Figure 3 are not conclusive. The objective of this research was to examine the correlation between the progress of the hydration process and the possible variations of the material thermophysical properties. The exothermicity of the hydration reaction is at the origin of a sharp increase in the temperature of the sample (Fig. 12), which interferes with measurements. During the test, indeed, the heat liberated by the hydration process (variable with time and difficult to assess accurately) is added to the power released by the heating film, which makes the application of equations $(5,7)$ and, consequently, the determination of very fresh cement thermal properties impossible.

In order to free the measurements from the influence of hydration heat on cement paste, a variant of the initial set-up (Fig. 3) has been developed, which consists in transferring heat away through the upper surface of the sample using a cooling box. This box is made of two $141 \times 1-\mathrm{mm}$ square plates (Fig. 13). One is made of copper and in contact with the cement paste, the other is made of transparent PVC and can be seen in Figure 13. The sidewalls of the box and the inner baffles used to direct the direction of the water flow are also in PVC. Two copper tubes are used as inlet and outlet for the cooling water pumped from a thermostatic bath. Thanks to this device the temperature of the cement paste is satisfactorily regulated (Fig. 12).

So, thanks to the modification, one side of the cement paste sample with a thickness of $l$, is now heated, from the instant $t=0$, by the film emitting a power $P\left[\mathrm{~W} \mathrm{~m}{ }^{-2}\right]$, whereas the temperature of the upper surface remains constant. The whole combination is placed between two thick insulation plates. Some thermocouples measure the temperature on both sides of the plate, the heated face and the isotherm one. When applying the solution of equa-

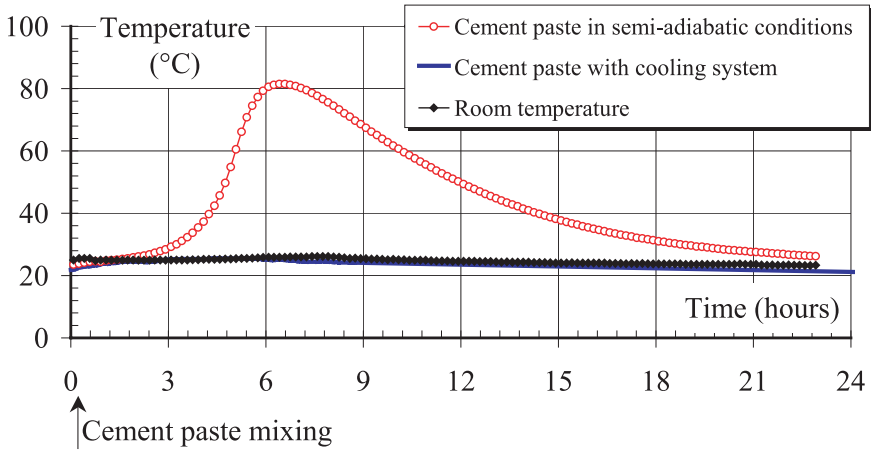

Fig. 12. Temperature evolution of cement paste $($ a $141 \times 141 \times$ 20-mm plate) kept isotherm thanks to cooling system, on the one hand, and in semi-adiabatic conditions, on the other hand, during hydration.

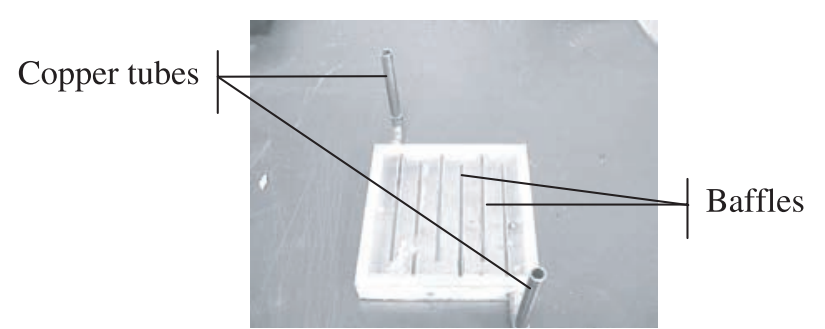

Fig. 13. Photograph of the cooling box added to the set-up for the study of fresh cement paste.

tion (3), we obtain the theoretical evolution of the temperature, $T_{h}$, of the heated side, that is, according to [16], equations $(19,20)$ :

$$
\begin{gathered}
T_{h}=\frac{2 P}{b \sqrt{\pi}} \sqrt{t}, \quad \text { if } \quad t \rightarrow 0 \\
T_{h}=\frac{P l}{\lambda}, \quad \text { if } \quad t \rightarrow \infty .
\end{gathered}
$$

Both equations are used to determine $\lambda b, \rho_{0} c$ and $a$ : equation (19) gives:

$$
b=\frac{2 P \Delta(\sqrt{t})}{\sqrt{\pi} \Delta T}
$$

equation (20) gives:

$$
\lambda=\frac{P l}{\Delta T}
$$

and consequently:

$$
\rho_{0} c=\frac{4 P(\Delta \sqrt{t})^{2}}{l \pi \Delta T}
$$

and

$$
a=\frac{l \pi}{4(\Delta \sqrt{t})^{2}} .
$$

In practice, both equations can be applied only when the temperature experimental evolutions agree with theoretical estimations. However, the tests conducted here reveal that the heating time $(>30 \mathrm{~min})$ required to reach the 
steady state ( $T_{h}$ constant) is much too long for a precise follow-up of the evolution of the material thermophysical properties. The application of this method to fresh cement paste is, therefore, abandoned for a specific set-up based on the method of heated and non-heated wires [7].

\section{Conclusion}

The improvements of the experimental principle described here have made it easy to implement and capable of performing repetitive tests. This technique can be used for mean conductivity materials undergoing no sharp thermal changes (exothermic reactions, for instance).

The TELEDELTOS paper is a high quality and versatility heating film. Unfortunately, the sources of supply appear uncertain.

Results on thermophysical properties of materials, at last, are reliable and can be reproduced. A certain redundancy in the relationships presented here makes it possible to assess all properties through two distinctive approaches at least and, therefore, to lessen the possibility of error in the validation of the measurements.

The miniaturization of the set-up requires homogeneous materials. If not, like concrete containing big-sized aggregates, for instance, the experimental technique describes in reference [7] suits their study much better. In a more general way, a classical approach [21] consists in considering a sample size 10 times higher than that of largest of the components. For example, in the presence of aggregates with a maximum size of $20 \mathrm{~mm}$, the lowest dimension of the sample should be higher than $200 \mathrm{~mm}$. It is then necessary to increase both the size of the device (while keeping a reasonable thickness of sample) and the power delivered by the heating film, in order to obtain a sufficient thermal signal.

In addition, in case of strongly heterogeneous medium, the local temperature measurement may be improved by installing several thermocouples, placed in series, on the lower and the upper sides of the sample [22]: it is thus possible to obtain a stronger thermal signal and to measure an average temperature value on both sides of the sample.

In spite of these practical solutions, the measurement of the thermophysical properties of strongly heterogeneous materials remains a complex problem, which has not been completely elucidated. The theoretical resolution of this problem requires, according to us, the application of "volume averaging" techniques [23].

\section{References}

1. P. Crausse, J.P. Laurent, B. Perrin, Rev. Gén. Therm. 35, 95 (1996)

2. G. Bastian, in Drying 89, edited by A.S. Mujumdar, M. Roques (Hemisph. Pub. Corp., New-York, 1990)

3. C. Moyne, Ph.D. Dissertation, INPL, Nancy, France, 1987

4. P. Kalifa, F.D. Menneteau, Cah. CSTB 402, 1 (1999)

5. N. Al Sheikh Hassan, G. Bastian, Ann. ITBTP 484, 45 (1990)

6. N. Al Sheikh Hassan, G. Bastian, Rev. Gén. Therm. 374, 98 (1993)

7. G. Bastian, A. Khelidj, Bull. Liaison Lab. Phys. Chem. 200, 25 (1995)

8. G. Bastian, Drying Technol. 15, 2145 (1997)

9. N. Aouaïssia-Abdallah, G. Bastian, Matér. Construct. 31, $579(1998)$

10. G. Bastian, Rev. Phys. Appl. 22, 431 (1987)

11. P. Mounanga, G. Bastian, A. Khelidj, in Proceedings of the 16th ECTP, London, 2002, edited by Imperial College, London, 2002 (CD-Rom medium)

12. P.C.D. Milly, Water Resour. Res. 18, 489 (1982)

13. J.F. Daïan, Ph.D. Dissertation, USTM, Grenoble, France, 1986

14. R. Alder, in Représentations analogiques et homologiques dans les techniques de la chaleur, edited by S.F.T. (Dunod, Paris, 1965)

15. O.T. Farouki, in Thermal Properties of Soils, edited by Trans. Tech. Publications (Clausthal-Zellerfeld, Germany, 1986)

16. Aide-mémoire $d u$ thermicien $A^{3} \cdot E^{2} . T h$ (Editions Européennes Thermique et Industrie, Paris, France, 1982)

17. C. Hazard, J.-P. Barette, J. Mayer, in Mémotech - Bois et matériaux associés (Editions Casteilla, Paris, France, 1996)

18. G. Bastian, Rev. Phys. Appl. 24, 1057 (1989)

19. K.-H. Götz, D. Hoor, K. Möhler, J. Natterer, Construire en bois (Presses Polytechniques et Universitaires Romandes, Lausanne, Suisse, 1993)

20. LIGNUM (L'Union Suisse en Faveur du Bois) (LIGNUM, Zurich, 1960), Tome 1

21. R. L'Hermite, A. Alzas, M. Fickelson, in Méthodes générales d'essai et de contrôle en laboratoire (Eyrolles, Paris, 1967), Tome 1

22. R. Bouzidi, G. Bastian, A. Khelidj, in Journée AFM, Identification des propriétés mécaniques de matériaux et de structures à partir de mesures de champs, ClermontFerrand (France), 2002

23. S. Whitaker, Adv. Heat Trans. 13, 119 (1977) 